\title{
The Acutely Comatose Patient: Clinical Approach and Diagnosis
}

\author{
S. Arthur Moore, $\mathrm{MD}^{1} \quad$ Eelco F. Wijdicks, MD, $\mathrm{PhD}^{1}$ \\ ${ }^{1}$ Department of Neurology, Mayo Clinic, Rochester, Minnesota \\ Semin Neurol 2013;33:110-120.
}

\begin{abstract}
Address for correspondence Eelco F. Wijdicks, MD, PhD, Department of Neurology, Mayo Clinic, Rochester, MN 55905 (e-mail: wijde@mayo.edu).
\end{abstract}

\begin{abstract}
A patient's acute and persistent unresponsiveness in the emergency department often triggers a neurology consultation. Given the many potential causes of unresponsiveness, the initial objective of the neurologist should be a comprehensive history and physical examination, which should allow localization of the lesion, if possible, and an initial narrowing of the differential diagnosis. In addition, neuroimaging review and laboratory evaluation have come to play an increasingly important role in identification of the potential causes of unresponsiveness. However, in some instances, the computed tomography or the magnetic resonance imaging scans are normal and sorting out the

Keywords

- unresponsiveness

- coma

- FOUR score

- emergency neurology cause and depth of unresponsiveness requires clinical skill. The neurologist is adept at correctly moving through a differential diagnosis and this has a profound effect on management. Once appropriate treatment has been initiated, the outcome can be assessed. Recovery from coma can be prolonged, but is less likely if early involvement of the brainstem is apparent.
\end{abstract}

A significant injury or dysfunction of the brain is needed to produce unresponsiveness. The top three causes of coma outside the hospital remain intoxication (including illicit and legal drugs), diabetic dysregulation, and traumatic head injury. The distribution of causes of unresponsiveness, however, is different in the emergency department, the critical care unit, the surgical recovery room, or the general hospital ward. In general, the management priority in any case of unresponsiveness should be to prevent a treatable cause of coma from leading to a permanent injury.

Within the emergency department, the approach to coma is to stabilize (more than airway, breathing, circulation $[\mathrm{ABC}]$ ), to diagnose (more than the Glasgow Coma Scale), to manage (more than intravenous glucose and antidotes), and to critically assess information one step at a time (more than an algorithm).

\section{Defining the State of Consciousness}

Consciousness is typically defined as the presence of arousal, in which one is able to interact with the environment, and awareness, with the ability to know "what is going on."
Traditionally, consciousness has been divided into content and level of arousal with its disconnect "wakeful unresponsiveness." Coma is by definition a complete loss of both awareness and arousal (similar to general anesthesia). Clinicians have long struggled with defining unconsciousness, but over the years, different categories have emerged. These categories may need redefinition as a result of functional magnetic resonance imaging (fMRI) data. What seems incontrovertibly true is that prolonged unconsciousness is very rare. Awakening may not mean registering events and a certain point of no return exists beyond which the patient will not likely awaken. A significant reduction in both awareness and arousal can be seen in a minimally conscious state. The various disorders of consciousness as well as mimickers of coma are presented in - Table $\mathbf{1}$.

\section{The History}

In all cases of acute unresponsiveness, the process of identifying the underlying etiology begins with a comprehensive history after the patient has been stabilized. There can be major impediments to this. The history is often convoluted, family members are often not present, and if they are, they
Issue Theme Acute Coma and Disorders of Consciousness; Guest Editors, Hans A. Püttgen, MD, and Romergryko G. Geocadin, MD
Copyright (c) 2013 by Thieme Medical Publishers, Inc., 333 Seventh Avenue, New York, NY 10001, USA. Tel: +1(212) 584-4662.
Dol http://dx.doi.org/ 10.1055/s-0033-1348963. ISSN 0271-8235. 
Table 1 Disorders of consciousness and mimickers

\begin{tabular}{|l|l|l|l|}
\hline State & Arousal & Awareness & Description \\
\hline Coma & Absent & Absent & $\begin{array}{l}\text { No response to noxious stimuli other than } \\
\text { reflexic, such as extensor or flexor posturing }\end{array}$ \\
\hline Persistent vegetative state 2,3 & Preserved & Absent & $\begin{array}{l}\text { Transitioning from coma to prolonged coma, } \\
\text { eyes may be open, especially during the day; } \\
\text { roving eye movements; } \\
\text { no sustained, reproducible response to } \\
\text { stimuli; stable autonomic functions }\end{array}$ \\
\hline Minimally conscious state & Present, but minimal & Present, but minimal & $\begin{array}{l}\text { May make eye contact or track visual stimuli; } \\
\text { abulic, emotionless; may mouth words or } \\
\text { fend off pain; may hold or use an object } \\
\text { when asked }\end{array}$ \\
\hline Delirium & $\begin{array}{l}\text { Altered, but not } \\
\text { absent or diminished }\end{array}$ & $\begin{array}{l}\text { Altered, but not } \\
\text { absent or diminished } \\
\text { Akinetic mutism }\end{array}$ & $\begin{array}{l}\text { Rapidly fluctuating mental status; frequent } \\
\text { of sensory stimuli including hallucinations }\end{array}$ \\
\hline Locked-in syndrome & Appears intact & Absent & Preserved \\
\hline Psychogenic unresponsiveness & $\begin{array}{l}\text { Preserved, but may } \\
\text { appear altered }\end{array}$ & $\begin{array}{l}\text { Preserved, but may } \\
\text { appear altered }\end{array}$ & $\begin{array}{l}\text { Complete paralysis with the exception of } \\
\text { vertical eye movements with normal } \\
\text { sensation and cognition }\end{array}$ \\
\hline
\end{tabular}

may be flustered as to what happened or "shocked." That being said, family members as well as the responding paramedics or any other witnesses to the loss of consciousness can potentially provide valuable information. How and where was the patient found? Was there an abrupt loss of consciousness that may indicate a vascular disorder or was the loss of consciousness preceded by several days of worsening confusion, such as might be seen in a metabolic disorder or an evolving intracranial mass? Were there empty pill or alcohol bottles around the patient that may suggest intoxication? The circumstances surrounding the discovery of the patient can provide valuable clues, but they should be taken in context of the wider clinical picture.

Family members can be especially helpful in providing information about the patient's medical history and allergies. Did the patient have a history of cardiac or vascular disease, which may increase your suspicion for an ischemic event or arrhythmia? What medications was the patient taking and were they actually taking their medications as prescribed? Was the patient taking any herbal supplements that may have interacted with their other medications? Is there a past psychiatric history, including prior suicide attempts or alcohol or drug abuse? Has the patient experienced events in the past similar to the current event?

In addition to past medical history, the recent medical history can provide important clues and can be gleaned from family members. Had the patient complained of headache or fever in the days prior to the event, which may imply an infectious etiology? Was there any confusion or difficulties with speech or language in the preceding days? Regardless of the information obtained in the history, the physical examination, including both a general and a neurologic examina- tion, is key in refining the differential diagnosis and focusing further testing and potential treatment. Before a neurologic examination is performed, it is helpful to have a good understanding of the major causes of coma. A summary is shown in - Table 2.

\section{The Physical Examination}

\section{General Considerations}

The examination of any unresponsive patient should begin with an assessment of vital signs. Not only does this allow for evaluation of the stability of the patient, it may also provide clues to the etiology of the patient's unresponsiveness. For instance, while hyperthermia can be seen in midbrain or pontine hemorrhages, infection and various drug overdoses including cocaine, tricyclic antidepressants, and salicylate intoxication can also lead to elevated temperature, whereas hypothermia is seen with alcohol intoxication or an overdose of barbiturates. Similarly, hypertension can be seen secondary to increased intracranial pressure, but can also be indicative of posterior reversible encephalopathy syndrome (PRES) or amphetamine overdose. Hypotension can point toward sepsis or progression to brain death.

One commonly overlooked examination finding is the patient's respiratory pattern. Although commonly difficult to observe because of mechanical ventilation, a spontaneous ventilator mode can be used to assess the patient's intrinsic breathing pattern. It should be noted, however, that the value of these patterns in localizing a lesion is not firmly established. Cheyne-Stokes respirations can be seen with heart failure or in any form of reduced responsiveness and is therefore poorly localizing. ${ }^{5,6}$ Cluster breathing as well as 
112 The Acutely Comatose Patient: Clinical Approach and Diagnosis Moore, Wijdicks

Table 2 Classification and major causes of coma ${ }^{5}$

\begin{tabular}{|c|}
\hline Structural brain injury \\
\hline Hemisphere \\
\hline Unilateral (with displacement) \\
\hline Intraparenchymal hematoma \\
\hline Middle cerebral artery occlusion \\
\hline Hemorrhagic contusion \\
\hline Cerebral abscess \\
\hline Brain tumor \\
\hline Bilateral \\
\hline Penetrating traumatic brain injury \\
\hline Multiple traumatic brain injuries \\
\hline Anoxic-ischemic encephalopathy \\
\hline Aneurysmal subarachnoid hemorrhage \\
\hline Multiple cerebral infarcts \\
\hline Bilateral thalamic infarcts \\
\hline Cerebral venous thrombosis \\
\hline Lymphoma \\
\hline Encephalitis \\
\hline Gliomatosis \\
\hline Acute disseminated encephalomyelitis \\
\hline Cerebral edema \\
\hline Multiple brain metastases \\
\hline Acute hydrocephalus \\
\hline Acute leukodystrophy \\
\hline Brainstem \\
\hline Pontine hemorrhage \\
\hline Basilar artery occlusion \\
\hline Central pontine myelinolysis \\
\hline Brainstem hemorrhagic contusion \\
\hline Cerebellum (with displacement of brainstem) \\
\hline Cerebellar infarct \\
\hline Cerebellar hematoma \\
\hline Cerebellar abscess \\
\hline Cerebellar glioma \\
\hline Acute metabolic-endocrine derangement \\
\hline Hypoglycemia \\
\hline Hyperglycemia (nonketotic hyperosmolar) \\
\hline Hyponatremia \\
\hline Hypernatremia \\
\hline Addison disease \\
\hline Hypercalcemia \\
\hline Acute hypothyroidism \\
\hline Acute panhypopituitarism \\
\hline Acute uremia \\
\hline
\end{tabular}

Table 2 (Continued)

\begin{tabular}{|l|}
\hline Structural brain injury \\
\hline Hyperbilirubinemia \\
\hline Hypercapnia \\
\hline Diffuse physiologic brain dysfunction \\
\hline Generalized tonic-clonic seizures \\
\hline Poisoning, illicit drug use \\
\hline Hypothermia \\
\hline Gas inhalation \\
\hline Acute (lethal) catatonia, malignant neuroleptic syndrome \\
\hline Psychogenic unresponsiveness \\
\hline Hysterical \\
\hline Malingering \\
\hline
\end{tabular}

Source: Used with permission from Wijdicks EFM. The Practice of Emergency and Critical Care Neurology. New York, NY: Oxford University Press; 2010.

central neurogenic hyperventilation can both indicate bihemispheric or pontine lesions. ${ }^{7,8}$ Neurogenic hyperventilation can also be seen with midbrain lesions. Ataxic breathing, characterized by no discernible respiratory pattern, may indicate a lesion of the dorsomedial medulla, while apneustic breathing is seen with lesions of the lateral tegmentum within the lower pons. ${ }^{9,10}$ See - Table $\mathbf{3}$ for a brief description of respiratory patterns.

The general skin appearance and any unusual odors emanating from the patient should also be noted. Are there signs of trauma, such as a Battle sign (bruising of the mastoid bone) or raccoon eyes (periorbial ecchymosis), which may each suggest skull base fractures? Dry skin can signify barbiturate intoxication (a rare intoxication these days), while diaphoresis can imply hypoglycemia or cholinergic toxicity. The classic foul breaths are also occasionally helpful and include a "dirty toilet" odor with uremia, a "fruity sweat" odor with ketoacidosis, the "fishy" odor with acute hepatic failure, an "onion" odor secondary to paraldehyde, and a "garlic" odor from organophosphates. - Table 4 summarizes the general examination findings and their potential implications.

\section{The Neurologic Examination}

\section{Coma Scales}

The primary goal of the neurologic examination in an unresponsive patient is to localize the lesion and thereby narrow the differential diagnosis. The examination should proceed in a stepwise fashion and be familiar to the neurologist because of constant repetition.

In the process of the comprehensive neurologic examination, the depth of coma should be determined using a coma scale. The Glasgow Coma Scale (GCS) is the most common of such scales. Originally developed for victims of traumatic head injury in 1974 and revised in 1976, it consists of three parts: eye movement, best motor response, and best verbal 
Table 3 Breathing abnormalities ${ }^{11}$

\begin{tabular}{|l|l|l|}
\hline Breathing abnormality & Description of breathing & Localization \\
\hline Cheyne-Stokes & $\begin{array}{l}\text { Crescendo-decrescendo breathing pattern } \\
\text { followed by apnea or hypopnea; persists in sleep }\end{array}$ & $\begin{array}{l}\text { Bihemispheric (unilateral or bilateral) } \\
\text { or brainstem }\end{array}$ \\
\hline Cluster & $\begin{array}{l}\text { Irregular clusters of breaths followed by apneic periods } \\
\text { of variable duration }\end{array}$ & Bihemispheric or pons \\
\hline Ataxic or irregular & $\begin{array}{l}\text { Irregular respiratory rate, rhythm; amplitudes interrupted } \\
\text { by apnea }\end{array}$ & Nonlocalizing or dorsomedial medulla \\
\hline Apneustic & $\begin{array}{l}\text { Prolonged inspiration with a 2- to 3-s pause, } \\
\text { then expiration }\end{array}$ & Lateral tegmentum of lower pons \\
\hline $\begin{array}{l}\text { Central neurogenic } \\
\text { hyperventilation }\end{array}$ & $\begin{array}{l}\text { Sustained hyperventilation, respiratory rates } \\
\text { exceeding 40 per minute }\end{array}$ & Bihemispheric, pons, midbrain \\
\hline
\end{tabular}

Source: Reprinted with permission from Wijdicks EFM. The Comatose Patient. New York, NY: Oxford University Press; 2008.

response (- Table 5). ${ }^{12,13}$ Each component is graded on a scale from 1 to 6 and the summation of the scores is used to communicate the depth of coma. Although not useful in the diagnosis of coma, the GCS has been shown to have acceptable interobserver reliability through a wide range of trained providers as well as predictive value for outcomes in tuberculous meningitis, subarachnoid hemorrhage, subdural hematoma, and survivors of cardiac arrest. ${ }^{14-26}$ However, the GCS does not account for the presence or absence of brainstem reflexes and may not detect subtle changes in the neurologic examination, findings that could be instrumental in determining a patient's prognosis.

To address the shortcomings of the GCS, the Full Outline of UnResponsiveness (FOUR) score was developed. This coma score includes four components-eye, motor, brainstem, and respiratory-that are each graded on a scale from 0 to 4 , producing a maximum combined total score of 16 (-Fig. 1). ${ }^{27,28}$ With an equal to higher interrater reliability than the GCS, as well as validation in multiple patient populations, the FOUR score has proven to be an important tool in the evaluation of comatose patients. ${ }^{27,29-37}$ Perhaps because of its greater emphasis on brainstem reflexes and respiratory patterns, the FOUR score has also been shown to have greater predictive value in terms of eventual progression toward more severe injury, especially in patients with low GCS scores or the ubiquitous GCS score of 3T, which is commonly reported by paramedics following intubation in the field after sedatives and paralytics have been given. ${ }^{38}$

\section{Cranial Nerves}

The formal neurologic evaluation of an unresponsive patient typically begins with the cranial nerves. Pupil size as well as position should be examined. Small or pinpoint pupils $(<2$ $\mathrm{mm}$ ) that are minimally or unreactive to light could be secondary to a pontine lesion that interrupts descending sympathetic outflow. The most commonly known cause of small pupils is prior use of opioids (on the street, heroin; while in the hospital, it is patient-controlled analgesia pumps or opioid patches). Dilated ( $>8 \mathrm{~mm}$ ) pupils are due to disruption of cranial nerve $(\mathrm{CN})$ III secondary to either a mesencephalic injury or a lesion of the peripheral nerve. Drugs and other toxins such as amphetamines or lidocaine can also result in dilated pupils and must be excluded through the patient's history and laboratory testing. Midsize, lightfixed pupils are seen in severe midbrain lesions that can be secondary to herniation and are frequently the first sign of loss of all brainstem reflexes (brain death).

In addition to pupil size and reactivity, any deviation of one or both eyes should also be noted. Spontaneous eye movements including "ping-pong" eyes or ocular dipping generally indicate bihemispheric dysfunction. Ocular bobbing, described as a rapid downward deviation of the eyes followed by a slow upward movement, typically implies a pontine lesion. Bihemispheric dysfunction can also lead to the classic "roving eye movements," though metabolic processes and various toxicities can cause this as well. Rather than supporting a particular localization or disease process, roving eye movements indicate that the brainstem is relatively intact. See - Table $\mathbf{6}$ for a summary of eye movement abnormalities in coma.

Tonic deviation of the eyes, typically in the horizontal plane, may indicate an ipsilateral hemispheric lesion affecting the frontal eye fields or a contralateral pontine lesion. Differentiation between a hemispheric lesion and a pontine lesion can be difficult in comatose patients as a hemiparesis is typically not apparent. However, the oculocephalic maneuver will be able to overcome a gaze preference from a cortical lesion as the pontine and midbrain structures responsible for the reflex remain intact. Horizontal deviation can also be seen in nonconvulsive status epilepticus and may be one of the few signs to indicate the need for an emergent electroencephalogram (EEG). Skew deviation implies a brainstem injury.

A funduscopic examination should also be performed once the external examination of the eyes has been completed. Vitreous hemorrhage, often subhyaloid in location, can be indicative of subarachnoid hemorrhage, so-called Terson syndrome, or even intracranial hemorrhage. ${ }^{39}$ Funduscopy may also reveal the presence of papilledema. Though often cited as a manifestation of acutely increased intracranial pressure in subarachnoid hemorrhage or acute meningitis, papilledema is more commonly seen with slowly progressive processes such as an enlarging intracranial mass. ${ }^{40-42}$

Further testing of the cranial nerves is accomplished through the various reflexes including the corneal, gag, and 
114 The Acutely Comatose Patient: Clinical Approach and Diagnosis Moore, Wijdicks

Table 4 Physical findings that may indicate a systemic illness or drug toxicity

\begin{tabular}{|c|c|}
\hline Sign or symptom & Consideration \\
\hline \multicolumn{2}{|l|}{ Vital signs } \\
\hline Hypertension & $\begin{array}{l}\text { Pheochromocytoma, eclampsia, calcineurin inhibitor toxicity, drug ingestion } \\
\text { (amphetamines, arsenic, cocaine, phencyclidine) }\end{array}$ \\
\hline Hypotension & $\begin{array}{l}\text { Addison disease, sepsis, drug ingestion ( } \beta \text { blockers, calcium channel blockers, } \\
\text { arsenic, barbiturates, cyclic antidepressants, lithium, methanol, opioids, } \\
\text { organophosphates, phenothiazine, sedative-hypnotics) }\end{array}$ \\
\hline Hyperthermia & $\begin{array}{l}\text { Infection, drug ingestion (amphetamines, cocaine, tricyclic antidepressants, } \\
\text { phencyclidine, salicylates), malignant catatonia, neuroleptic malignant } \\
\text { syndrome }\end{array}$ \\
\hline Hypothermia & $\begin{array}{l}\text { Hypothyroidism, hypoglycemia, environmental exposure, drug ingestion } \\
\text { (barbiturates, opioids, sedative-hypnotics, phenothiazine) }\end{array}$ \\
\hline Tachycardia & $\begin{array}{l}\text { Infection, drug ingestion (alcohol, amphetamines, cocaine, ethylene glycol, } \\
\text { arsenic, cyclic antidepressants, phencyclidine, phenothiazine) }\end{array}$ \\
\hline Bradycardia & Uremic coma, myxedema coma, drug ingestion ( $\beta$ blockers, opioids) \\
\hline Tachypnea & $\begin{array}{l}\text { Diabetic ketoacidosis, drug ingestion (ethylene glycol, salicylates, } \\
\text { amphetamines, methanol) }\end{array}$ \\
\hline Dyspnea & Drug ingestion (alcohol, barbiturates, opioids, sedative-hypnotics) \\
\hline \multicolumn{2}{|l|}{ Odor } \\
\hline “Dirty restroom” & Uremia \\
\hline "Fruity sweat" & Ketoacidosis \\
\hline "Musty or fishy" & Acute hepatic failure \\
\hline “Onion" & Paraldehyde \\
\hline "Garlic" & Organophosphates, insecticides, thallium \\
\hline \multicolumn{2}{|l|}{ Skin } \\
\hline Diaphoresis & $\begin{array}{l}\text { Thyroid storm, hypoglycemia, malignant catatonia, acute sympathetic } \\
\text { hyperactivity, drug exposure (organophosphates, sympathomimetics, } \\
\text { cholinergics) }\end{array}$ \\
\hline Dry skin & $\begin{array}{l}\text { Hypothyroidism, drug exposure (barbiturates, anticholinergics, cyclic } \\
\text { antidepressants) }\end{array}$ \\
\hline Acne & Long-term antiepileptic use \\
\hline Bullae & Drug exposures (barbiturates, sedative-hypnotics) \\
\hline Butterfly rash & Systemic lupus erythematosus \\
\hline Dark pigmentation & Addison disease \\
\hline Cold, malar flush, yellow tinge, puffy face & Myxedema coma \\
\hline Edema & Acute renal failure \\
\hline Purpura & $\begin{array}{l}\text { Meningococcal meningitis, thrombotic thrombocytopenic purpura, vasculitis, } \\
\text { disseminated intravascular coagulation, aspirin intoxication }\end{array}$ \\
\hline Rash & Meningitis, viral encephalitis, rickettsia \\
\hline
\end{tabular}

Table 5 The Glasgow Coma Scale

\begin{tabular}{|l|l|l|l|}
\hline & Best eye response & Best verbal response & Best motor response \\
\hline 6 & - & - & Obeys commands \\
\hline 5 & - & Oriented & Localizes pain \\
\hline 4 & Spontaneous eye opening & Confused & Withdraws from pain \\
\hline 3 & Eye opening to verbal command & Points & Flexion response to pain \\
\hline 2 & Eye opening to pain & Incomprehensible sounds & Extension response to pain \\
\hline 1 & No response & No response & No response \\
\hline
\end{tabular}



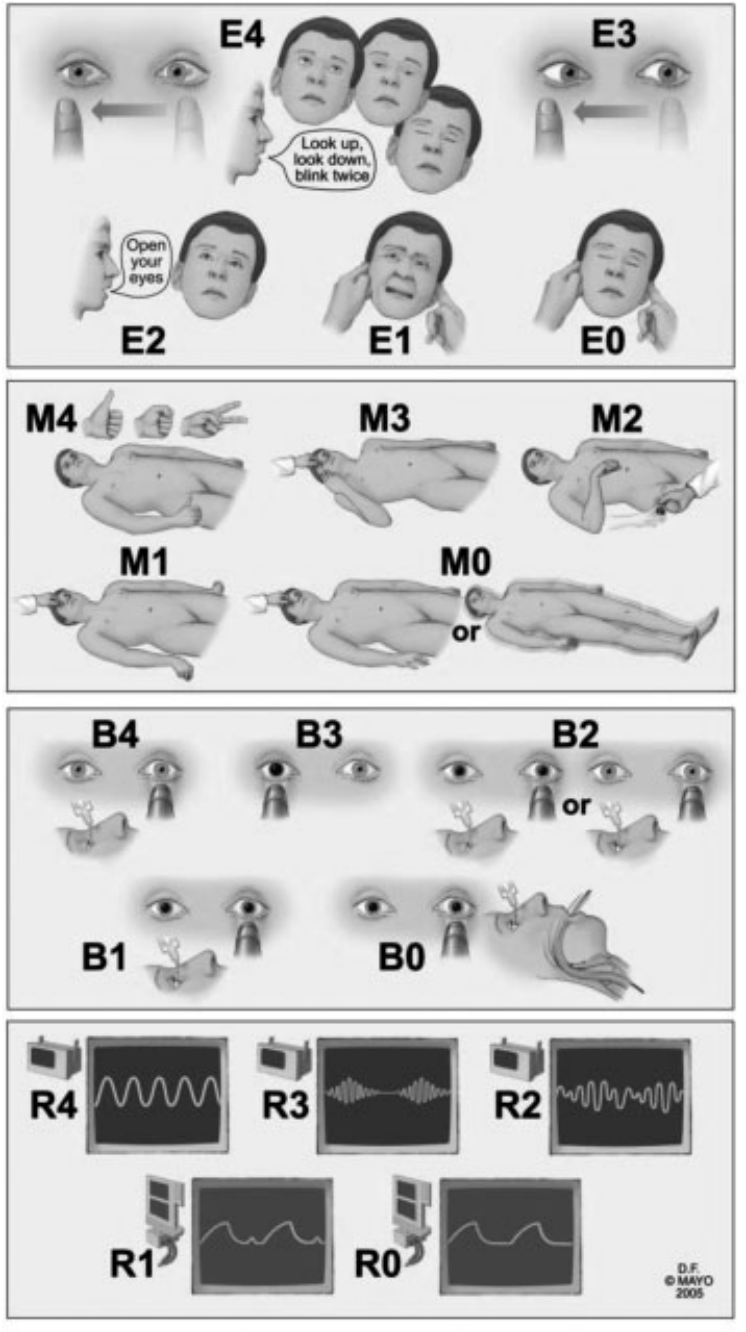

tet1740210005-1

\section{Eye response}

$4=$ Eyelids open or opened, tracking or blinking to command

$3=$ Eyelids open but not tracking

2 = Eyelids closed but open to loud voice

$1=$ Eyelids closed but open to pain

$0=$ Eyelids remain closed with pain

\section{Motor response}

4 = Thumbs-up, fist or peace sign

$3=$ Localising to pain

$2=$ Flexion response to pain

$1=$ Extension response to pain

$0=$ No response to pain, or generalised myoclonus status

\section{Brainstem reflexes}

$4=$ Pupil and corneal reflexes present

$3=0$ ne pupil wide and fixed

2 = Pupil or corneal reflexes absent

$1=$ Pupil and corneal reflexes absent

$0=$ Absent pupil, corneal and cough reflex

\section{Respiration}

$4=$ Not intubated, regular breathing pattern

$3=$ Not intubated, Cheyne-Stokes breathing pattern

2 = Not intubated, irregular breathing

$1=$ Breathes above ventilator rate

$0=$ Breathes at ventilator rate or apnoea

Fig. 1 The FOUR Score. ${ }^{5}$ (Reprinted with permission from Wijdicks EFM. The Practice of Emergency and Critical Care Neurology. New York, NY: Oxford University Press; 2010:110)

cough reflexes. Dysfunction of any of these reflexes implies a lesion involving the cranial nerves involved or the pathways connecting them. The oculocephalic reflex deserves special mention as several brainstem structures are assessed simultaneously. In a patient with a normally functioning brainstem, eyes will move in a direction opposite the head movement and appear to remain fixated on a point in space (much like a doll's eyes). If a lesion disrupts any of the structures or pathways involved in the reflex, including CNs III, IV, and VI and the medial longitudinal fasciculus, the eyes will move along with the head, remaining in midposition with respect to the bony orbits.

\section{Motor Responses}

Testing of the motor system in an unresponsive patient typically involves applying a noxious stimulus to the

Table 6 Eye movement abnormalities in coma ${ }^{11}$

\begin{tabular}{|l|l|}
\hline Type of movement & Lesion location \\
\hline Periodic alternating gaze (lateral deviation every few minutes, left and right) & Bihemispheric, midbrain, vermis \\
\hline Ping-pong (lateral deviation every few seconds, left and right) & Bihemispheric, vermis \\
\hline Convergence nystagmus (bilateral abduction, slow with rapid jerk back) & Mesencephalon \\
\hline Retractory nystagmus (retraction orbit) & Mesencephalon \\
\hline Bobbing (rapid down, slow up) & Pons \\
\hline Dipping (slow down, rapid up) & Bihemispheric \\
\hline
\end{tabular}

Source: Reprinted with permission from Wijdicks EFM. The Comatose Patient. New York, NY: Oxford University Press; 2008. 
supraorbital nerve, the nail bed, or the temporomandibular joint and assessing the patient's reaction. ${ }^{43}$ Possible responses include a localizing response, in which the patient reaches toward the stimulus, reflexive responses such as decorticate or decerebrate posturing, or no response at all.

Decorticate posturing involves a slow flexion of the elbow, wrist, and fingers, whereas decerebrate posturing is defined as adduction and internal rotation of the shoulder with arm extension and wrist pronation. Although posturing reflexes have purportedly been useful in lesion localization, these responses can be seen with either focal lesions or global conditions affecting the nervous system. ${ }^{44,45}$ It is also not uncommon for both responses to be present in the same patient at the same time. ${ }^{11}$ Given this, the presence of decerebrate or decorticate posturing has relatively little utility in prognostication until the underlying etiology is found.

In addition to movements in response to stimulation, spontaneous movements can also be seen in unresponsive patients, the classic example being generalized myoclonus. Although a predictor of an extremely poor outcome following cardiac arrest and resulting anoxic ischemic injury, generalized myoclonus can also be seen with various intoxications including lithium, cephalosporins, and pesticides. ${ }^{46-48}$

\section{Initial Approach to the Unresponsive Patient}

\section{Neuroimaging}

Unfortunately, many unresponsive or comatose patients lack true localizing features on examination; in such instances, further testing with neuroimaging and laboratory evaluation may help in determining the underlying etiology. Even in a patient whose examination allows the neurologist to localize the lesion, imaging and laboratory investigation continue to play a key role. For instance, the examination may suggest a lesion involving the midbrain, but the lesion can be a stroke or a mass.

At most institutions, the computed tomography (CT) scan is the fastest and most readily available imaging modality. In the evaluation of an unresponsive patient, CT scans are excellent at detecting hydrocephalus or intracranial hemorrhage, with a sensitivity and specificity approaching $100 \%$ in conditions such as acute ( $<12 \mathrm{~h}$ since onset) subarachnoid hemorrhage. ${ }^{49,50}$ Computed tomography scans are also useful in the detection of edema, though the underlying cause of the edema may be elusive. Limitations of CT include poor visualization of the posterior fossa secondary to bone artifact, as well as reduced anatomical differentiation in comparison to magnetic resonance imaging (MRI) that may not allow precise etiological determination.

Magnetic resonance imaging scans allow greater definition of cortical and subcortical structures and may show cortical injury, laminar necrosis, or white matter disease that is not apparent on a CT scan. Magnetic resonance angiography allows for excellent visualization of the arterial system and is the preferred method for visualization of suspected acute basilar artery occlusion; ${ }^{51,52}$ however, this may not be possible at all institutions; in such instances, CT angiogram or conventional angiography can allow for rapid visualization of the arterial system. The major drawbacks of MRI scans include accessibility, cost, and time necessary to complete the scan. Frequent abnormalities on brain imaging in a comatose patient are presented in -Table $\mathbf{7}$ along with possible underlying etiologies for the findings.

\section{Laboratory and Ancillary Investigations}

Laboratory evaluation plays a prominent role in the evaluation of an acute unresponsive patient and can often lead to a relatively rapid diagnosis of any acute metabolic abnormality (-Table 8). As part of the initial workup of any unresponsive patient, the following laboratories are essential: hematocrit, full blood count with differential, platelet count, and peripheral blood smear; full electrolyte panel including calcium, magnesium, and phosphorus in addition to the conventional sodium and potassium; creatinine and blood urea nitrogen; liver function tests including aspartate aminotransferase blood test (AST), alanine aminotransferase blood test (ALT), bilirubin, and ammonia; serum and urine osmolality; arterial blood gases; thyroid function tests; and urinalysis. Further testing should be tailored to the clinical history, physical examination, and imaging. For instance, urine and blood drug screens should be obtained if any toxicity is suspected. In patients who present with fever and/or an elevated white blood cell count, blood cultures are a necessity. Troponins should be obtained if there is any suspicion of an acute cardiac pathology.

It is important to calculate the anion and osmolar gaps as these can aid in diagnosis of an acute intoxication. Anion gap $=\left[\mathrm{Na}^{+}\right]-\left[\mathrm{Cl}^{-}\right]-[\mathrm{HCO} 3-]$. A normal anion gap is between 11 and $13 \mathrm{mEq} / \mathrm{l}$ and increases in the presence of unmeasured anions, such as in methanol, ethanol, paraldehyde, and salicylate intoxications. Osmol gap $=2 \mathrm{X} \mathrm{Na}^{+}+[$glucose $] / 18+[$ blood urea nitrogen]/2.8. A difference between the calculated and measured osmolality greater than $10 \mathrm{mosmol} / \mathrm{l}$ can indicate intoxication with atypical alcohols including methanol, ethylene glycol, and isopropyl glycol.

Although more invasive, a lumbar puncture (LP) should be performed in all unresponsive patients with either signs or symptoms of infection or meningeal irritation or when the CT scan is normal and no explanation exists for the decreased responsiveness. Tests that should be included on evaluation of the cerebrospinal fluid (CSF) include an opening pressure, CSF visual description, protein and glucose content, cellular evaluation including white blood cells and erythrocytes, bacterial culture, India ink stain and cryptococcal antigen, and viral titers and polymerase chain reactions. A CT or MRI scan would ideally precede an LP to exclude an epidural empyema that may cause further shift after LP.

The role of an urgent EEG in an unresponsive patient is somewhat limited with the exception of nonconvulsive status epilepticus. Nonconvulsive status epilepticus should be suspected in any patient with a history of seizures who becomes acutely unresponsive, but can also be considered in otherwise unexplained cases of acute unresponsiveness. Physical examination of a patient in nonconvulsive status epilepticus is commonly nonspecific, but may reveal altered mental status ranging from confused to comatose, 
Table 7 Frequent abnormalities on brain imaging in coma ${ }^{53}$

\begin{tabular}{|c|c|}
\hline Finding & Suggested disorder \\
\hline \multicolumn{2}{|l|}{ Computed tomography } \\
\hline Mass lesion & Hematoma, hemorrhagic contusion, middle cerebral artery infarct \\
\hline Hemorrhage in basal cisterns & Aneurysmal subarachnoid hemorrhage, cocaine abuse \\
\hline Intraventricular hemorrhage & Arteriovenous malformation \\
\hline Multiple hemorrhage infarcts & Cerebral venous thrombosis \\
\hline Multiple cerebral infarcts & Endocarditis, coagulopathy, vasculitis, thrombotic thrombocytopenic purpura \\
\hline Diffuse cerebral edema & Cardiac arrest, fulminant meningitis, acute hepatic necrosis, encephalitis \\
\hline Acute hydrocephalus & Aqueduct obstruction, colloid cyst, pineal region tumor \\
\hline Pontine or cerebellar hemorrhage & Hypertension, arteriovenous malformation, cavernous malformation \\
\hline Shear lesions in the white matter & Traumatic brain injury \\
\hline \multicolumn{2}{|l|}{ Magnetic resonance imaging } \\
\hline Bilateral caudate and putaminal lesions & Carbon monoxide poisoning, methanol \\
\hline $\begin{array}{l}\text { Hyperdense signal along sagittal, straight, } \\
\text { or transverse sinuses }\end{array}$ & Intracranial venous thrombosis \\
\hline Lesions in corpus callosum, white matter & Severe traumatic brain injury \\
\hline $\begin{array}{l}\text { Diffuse confluent hyperintense lesions in } \\
\text { white matter, basal ganglia }\end{array}$ & $\begin{array}{l}\text { Acute disseminated encephalomyelitis, posterior reversible encephalopathy } \\
\text { syndrome, immunosuppressive or chemotherapeutic agent toxicity, } \\
\text { metabolic leukodystrophies }\end{array}$ \\
\hline Pontine trident-shaped lesion & Central pontine myelinolysis \\
\hline Thalamus, occipital, brainstem lesions & Acute basilar artery occlusion \\
\hline Thalamus, frontal lobe lesions & Herpes simplex encephalitis \\
\hline
\end{tabular}

Source: Reprinted with permission from Wijdicks EFM. Catastrophic Neurologic Disorder in the Emergency Department. New York, NY: Oxford University Press; 2004.

subtle myoclonic movements in an extremity, or eye deviation. ${ }^{54}$ The classic role of EEG in the diagnosis of herpes simplex encephalitis has mostly been supplanted by MRI and CSF studies, and although generalized slowing and triphasic waves can be seen on EEG with structural and metabolic causes of unresponsiveness, the etiology is generally well established prior to the EEG.

\section{An Exercise in Diagnosis}

Two cases are presented. We have used a systematic approach as shown in -Fig. 2 to illustrate its usefulness in clinical practice.

Table 8 Laboratory values compatible with coma in patients with acute metabolic derangements ${ }^{a}$

\begin{tabular}{|l|l|}
\hline Derangement & Serum concentration \\
\hline Hyponatremia & $<110 \mathrm{mmol} / \mathrm{l}$ \\
\hline Hypernatremia & $>160 \mathrm{mmol} / \mathrm{l}$ \\
\hline Hypercalcemia & $>13 \mathrm{mg} / \mathrm{dl}$ \\
\hline Hypercapnia & $>65 \mathrm{~mm} \mathrm{Hg}$ \\
\hline Hypoglycemia & $<40 \mathrm{mg} / \mathrm{dl}$ \\
\hline Hyperglycemia & $>900 \mathrm{mg} / \mathrm{dl}$ \\
\hline
\end{tabular}

${ }^{\text {a }}$ Sudden decline in value is necessary.

\section{Case 1}

A middle-aged man was brought into the emergency department after being found prone and unresponsive for an unknown period. Because of vomiting, tachypnea (respiratory rate of 28), with no protection of his airway, the patient was intubated in the field. No further history was available. The patient was afebrile. Blood pressure was $148 / 89$ with a heart rate of 85 .

On physical examination, the patient appeared thin. Skin exam showed rare spider telangiectasias over the chest. The patient smelled faintly sweet. Neurologic examination revealed a comatose patient (GCS 3T, FOUR Score E0M0B4R3). The examination was otherwise nonlocalizing. The emergent CT scan was normal.

With a normal CT scan, the potential etiologies include toxic, epileptic, infectious, endocrine/metabolic, and anoxic/ ischemic. The emergent EEG was normal, ruling out status epilepticus. Routine laboratory investigation revealed a normal complete blood count including normal leukocyte count, which rules out infection assuming a normal immune system. Thyroid stimulating hormone and glucose were normal, ruling out the most common causes of endocrine/metabolic coma.

With all other possibilities ruled out, intoxication remains the most likely explanation for the patient's unresponsiveness. Electrolytes were normal except for slightly low calcium, mildly elevated AST and ALT with normal 


\section{Emergent Care of the Comatose Patient}

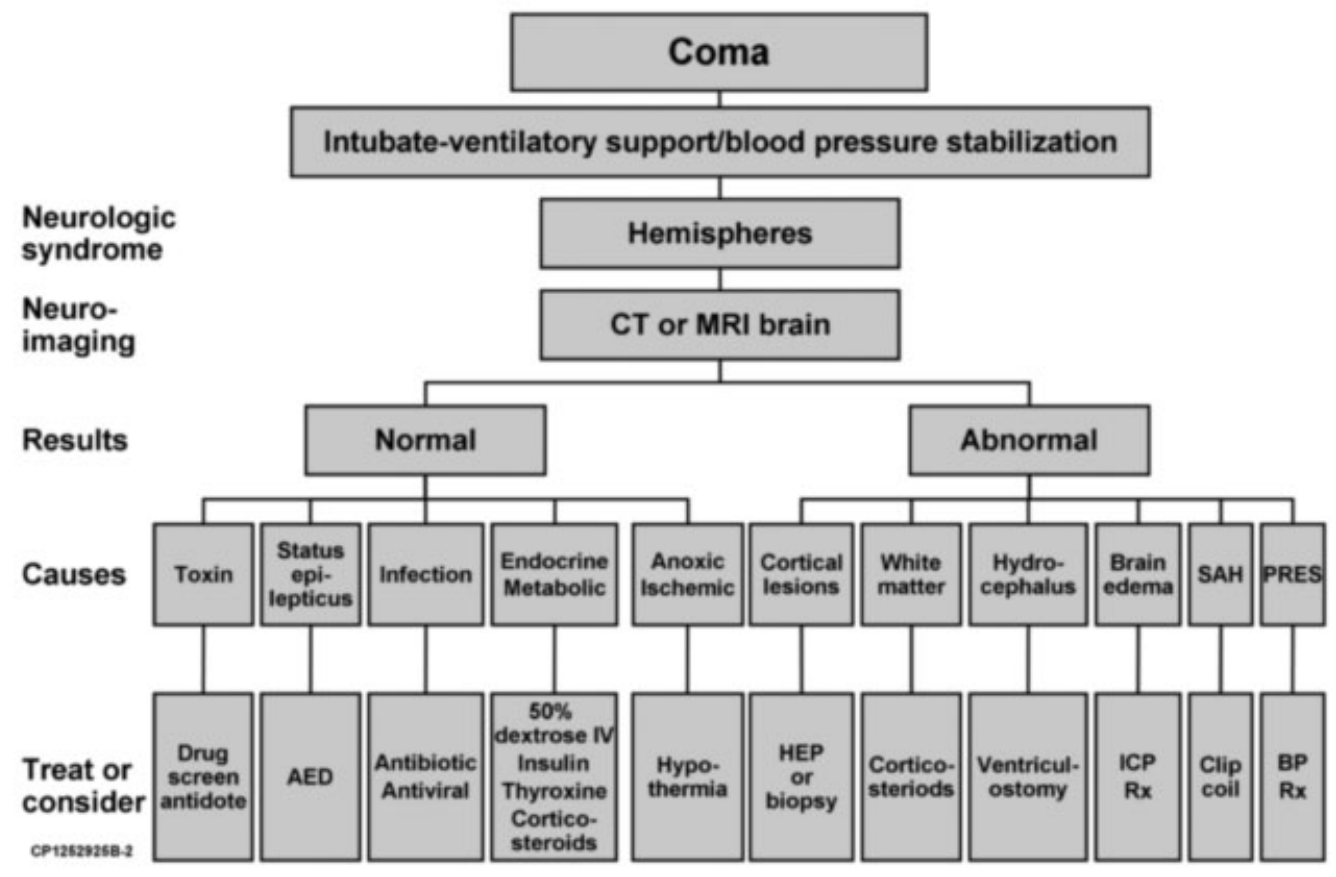

Emergent Care of the Comatose Patient

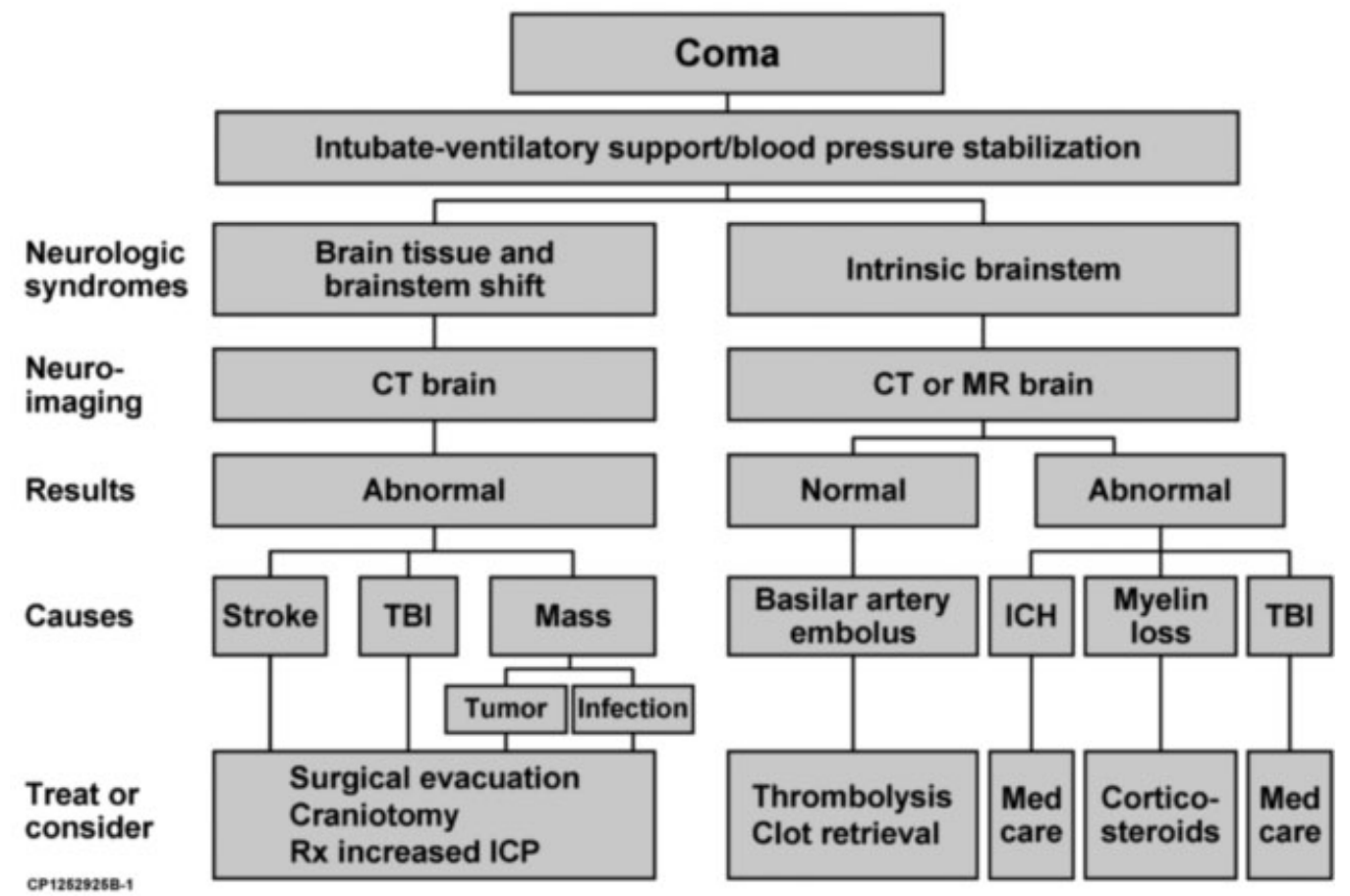

Fig. 2 Emergent diagnosis and care of the comatose patient.

ammonia and bilirubin, and slightly elevated creatinine. Osmol and anion gaps were significantly elevated at 29 and 19 , respectively. The significant elevations in the anion and osmol gap indicate the presence of an unmeasured anion, particularly an atypical alcohol. In this case, ethylene glycol taken by a chronic alcoholic is the correct diagnosis.
Case 2

A middle-aged man was brought into the emergency department after being found prone and unresponsive for an unknown period. Breathing was described as erratic with periods of apnea and the patient was intubated in the field. No further history was available. The patient was afebrile. Blood pressure and heart rate were stable and required no treatment. 
On physical examination, the patient was comatose (GCS 4T, FOUR Score E0M1B2R1). General examination was normal. Cranial nerve examination revealed a right pinpoint pupil that was reactive to light and a left midposition pupil that was unreactive to light. Corneal reflex was absent on the left. Cough and gag reflexes remained intact. Motor examination showed bilateral extensor posturing to painful stimuli. An emergent CT scan was normal.

Laboratory workup, including complete blood count, full electrolyte panel, liver function tests, arterial blood gases, and thyroid function test, was normal. Osmol and anion gaps were normal. Urine drug screen was negative.

Given the physical examination findings, the lesion localized to the brainstem, but was more diffuse (pontine pupil on the right and midbrain pupil on the left). With a normal CT scan and normal laboratory investigation, the lesion was likely the result of an embolus to the basilar artery. This was confirmed with a CT angiogram and resulted in urgent endovascular retrieval.

\section{Conclusions}

Following stabilization of the patient, the task of the neurologist is to interpret the information beginning with the history and physical examination and to order the appropriate tests. Important causes that should always be included in the differential of a patient who presents following sudden unresponsiveness are anoxic-ischemic injury, intoxication, central nervous infection, sudden metabolic derangement or endocrine crisis, nonconvulsive status epilepticus, embolus to the basilar artery, and, rarely, psychogenic.

Neuroimaging may help identify the underlying abnormality, just as a basic laboratory investigation that should include osmol and anion gap calculations.

Initial management of an unresponsive patient often starts before an etiology is clear, and is commonly based on clinical interpretation of the aforementioned tests. For instance, if a CT or MRI shows an acute structural lesion with mass effect, the first priority is to treat the intracranial pressure before the exact identity of the mass is known. In patients with potential infection, broad spectrum antibiotics, antivirals, and corticosteroids are started prior to identification of the infection.

\section{References}

1 Posner JB, Saper CB, Schiff ND, Plum F. Plum and Posner's Diagnosis of Stupor and Coma. 4th ed. New York, NY: Oxford University Press; 2007:3-37

2 Medical aspects of the persistent vegetative state (1). The MultiSociety Task Force on PVS. N Engl J Med 1994;330(21):1499-1508

3 Medical aspects of the persistent vegetative state (2). The MultiSociety Task Force on PVS. N Engl J Med 1994;330(22):1572-1579

4 Giacino JT, Ashwal S, Childs N, et al. The minimally conscious state: definition and diagnostic criteria. Neurology 2002;58(3):349-353

5 Wijdicks EFM. The Practice of Emergency and Critical Care Neurology. New York, NY: Oxford University Press; 2010:104-136

6 Tobin MJ, Snyder JV. Cheyne-Stokes respiration revisited: controversies and implications. Crit Care Med 1984;12(10):882-887

7 Cherniack NS, Longobardo G, Evangelista CJ. Causes of CheyneStokes respiration. Neurocrit Care 2005;3(3):271-279
8 Tarulli AW, Lim C, Bui JD, Saper CB, Alexander MP. Central neurogenic hyperventilation: a case report and discussion of pathophysiology. Arch Neurol 2005;62(10):1632-1634

9 Freeman WD, Sen S, Roy TK, Wijdicks EF. Cluster breathing associated with bihemispheric infarction and sparing of the brainstem. Arch Neurol 2006;63(10):1487-1490

10 Saito $\mathrm{Y}$, HashimotoT, Iwata $\mathrm{H}$, et al. Apneustic breathing in children with brainstem damage due to hypoxic-ischemic encephalopathy. Dev Med Child Neurol 1999;41(8):560-567

11 Wijdicks EFM. The Comatose Patient. New York, NY: Oxford University Press; 2008:64-83

12 Wijdicks EF. The bare essentials: coma. Pract Neurol 2010;10(1): 51-60

13 Jennett B, Teasdale G, Braakman R, Minderhoud J, Knill-Jones R. Predicting outcome in individual patients after severe head injury. Lancet 1976;1(7968):1031-1034

14 Teasdale G, Jennett B. Assessment of coma and impaired consciousness. A practical scale. Lancet 1974;2(7872):81-84

15 Schefold JC, Storm C, Krüger A, Ploner CJ, Hasper D. The Glasgow Coma Score is a predictor of good outcome in cardiac arrest patients treated with therapeutic hypothermia. Resuscitation 2009;80(6):658-661

16 Mullie A, Verstringe P, Buylaert W, et al; Cerebral Resuscitation Study Group of the Belgian Society for Intensive Care. Predictive value of Glasgow coma score for awakening after out-of-hospital cardiac arrest. Lancet 1988;1(8578):137-140

17 Geocadin RG, Buitrago MM, Torbey MT, Chandra-Strobos N, Williams MA, Kaplan PW. Neurologic prognosis and withdrawal of life support after resuscitation from cardiac arrest. Neurology 2006; 67(1):105-108

18 Edgren E, Hedstrand U, Kelsey S, Sutton-Tyrrell K, Safar P; BRCT I Study Group. Assessment of neurological prognosis in comatose survivors of cardiac arrest. Lancet 1994;343(8905):1055-1059

19 Phuenpathom N, Choomuang M, Ratanalert S. Outcome and outcome prediction in acute subdural hematoma. Surg Neurol 1993;40(1):22-25

$20 \mathrm{Chou} \mathrm{CH}$, Lin GM, Ku CH, Chang FY. Comparison of the APACHE II, GCS and MRC scores in predicting outcomes in patients with tuberculous meningitis. Int J Tuberc Lung Dis 2010;14(1):86-92

21 Hirai S, Ono J, Yamaura A. Evaluation of consciousness by the Glasgow Coma Scale in aneurysmal subarachnoid hemorrhage. Appraisal using logistic regression analysis. Clin Neurol Neurosurg 1997;99(Suppl 1):S42-S43

22 Rosen DS, Macdonald RL. Subarachnoid hemorrhage grading scales: a systematic review. Neurocrit Care 2005;2(2):110-118

23 Juarez VJ, Lyons M. Interrater reliability of the Glasgow Coma Scale. J Neurosci Nurs 1995;27(5):283-286

24 Menegazzi JJ, Davis EA, Sucov AN, Paris PM. Reliability of the Glasgow Coma Scale when used by emergency physicians and paramedics. J Trauma 1993;34(1):46-48

25 Fielding K, Rowley G. Reliability of assessments by skilled observers using the Glasgow Coma Scale. Aust J Adv Nurs 1990;7(4): 13-17

26 Gill MR, Reiley DG, Green SM. Interrater reliability of Glasgow Coma Scale scores in the emergency department. Ann Emerg Med 2004;43(2):215-223

27 Marion DW, Carlier PM. Problems with initial Glasgow Coma Scale assessment caused by prehospital treatment of patients with head injuries: results of a national survey. J Trauma 1994;36(1):89-95

28 Wijdicks EF, Bamlet WR, Maramattom BV, Manno EM, McClelland RL. Validation of a new coma scale: The FOUR score. Ann Neurol 2005;58(4):585-593

29 Wijdicks EF, Kokmen E, O'Brien PC. Measurement of impaired consciousness in the neurological intensive care unit: a new test. J Neurol Neurosurg Psychiatry 1998;64(1):117-119

30 Looser RR, Metzenthin P, Helfricht S, et al. Cortisol is significantly correlated with cardiovascular responses during high levels of stress in critical care personnel. Psychosom Med 2010;72(3):281-289 
31 Wolf CA, Wijdicks EF, Bamlet WR, McClelland RL. Further validation of the FOUR score coma scale by intensive care nurses. Mayo Clin Proc 2007;82(4):435-438

32 Stead LG, Wijdicks EF, Bhagra A, et al. Validation of a new coma scale, the FOUR score, in the emergency department. Neurocrit Care 2009;10(1):50-54

33 Iyer VN, Mandrekar JN, Danielson RD, Zubkov AY, Elmer JL, Wijdicks EF. Validity of the FOUR score coma scale in the medical intensive care unit. Mayo Clin Proc 2009;84(8):694-701

34 Fugate JE, Rabinstein AA, Claassen DO, White RD, Wijdicks EF. The FOUR score predicts outcome in patients after cardiac arrest. Neurocrit Care 2010;13(2):205-210

35 Sadaka F, Patel D, Lakshmanan R. The FOUR score predicts outcome in patients after traumatic brain injury. Neurocrit Care 2012; 16(1):95-101

36 Idrovo L, Fuentes B, Medina J, et al. Validation of the FOUR score (Spanish version) in acute stroke: an interobserver variability study. Eur Neurol 2010;63(6):364-369

37 Fischer M, Rüegg S, Czaplinski A, et al. Inter-rater reliability of the Full Outline of UnResponsiveness score and the Glasgow Coma Scale in critically ill patients: a prospective observational study. Crit Care 2010;14(2):R64

38 Wijdicks EF, Rabinstein AA, Bamlet WR, Mandrekar JN. FOUR score and Glasgow Coma Scale in predicting outcome of comatose patients: a pooled analysis. Neurology 2011;77(1):84-85

39 Hassan A, Lanzino G, Wijdicks EF, Rabinstein AA, Flemming KD. Terson's syndrome. Neurocrit Care 2011;15(3):554-558

40 Trobe JD. Papilledema: the vexing issues. J Neuroophthalmol 2011;31(2):175-186

41 van de Beek D, de Gans J, Spanjaard L, Weisfelt M, Reitsma JB, Vermeulen M. Clinical features and prognostic factors in adults with bacterial meningitis. N Engl J Med 2004;351(18):1849-1859

42 Ludwig CL, Smith MT, Godfrey AD, Armbrustmacher VW. A clinicopathological study of 323 patients with oligodendrogliomas. Ann Neurol 1986;19(1):15-21

43 Wijdicks EF. Temporomandibular joint compression in coma. Neurology 1996;46(6):1774
44 Kirk MM, Hoogwerf BJ, Stoller JK. Reversible decerebrate posturing after profound and prolonged hypoglycemia. Cleve Clin J Med 1991;58(4):361-363

45 Jabre A, Sawaya R, Arthur S. Decerebrate posturing with the syndrome of inappropriate secretion of antidiuretic hormone. Surg Neurol 1985;23(1):56-58

46 Wijdicks EF, Parisi JE, Sharbrough FW. Prognostic value of myoclonus status in comatose survivors of cardiac arrest. Ann Neurol 1994;35(2):239-243

47 Fugate JE, Wijdicks EF, Mandrekar J, et al. Predictors of neurologic outcome in hypothermia after cardiac arrest. Ann Neurol 2010; 68(6):907-914

48 Caviness JN, Evidente VG. Cortical myoclonus during lithium exposure. Arch Neurol 2003;60(3):401-404

49 Sidman R, Connolly E, Lemke T. Subarachnoid hemorrhage diagnosis: lumbar puncture is still needed when the computed tomography scan is normal. Acad Emerg Med 1996;3(9): 827-831

50 Perry JJ, Stiell IG, Sivilotti ML, et al. Sensitivity of computed tomography performed within six hours of onset of headache for diagnosis of subarachnoid haemorrhage: prospective cohort study. BMJ 2011;343:d4277

51 Bhadelia RA, Bengoa F, Gesner L, et al. Efficacy of MR angiography in the detection and characterization of occlusive disease in the vertebrobasilar system. J Comput Assist Tomogr 2001;25(3): 458-465

52 du Mesnil de Rochemont R, Neumann-Haefelin T, Berkefeld J, Sitzer $\mathrm{M}$, Lanfermann $\mathrm{H}$. Magnetic resonance imaging in basilar artery occlusion. Arch Neurol 2002;59(3):398-402

53 Wijdicks EFM. Catastrophic Neurologic Disorders in the Emergency Department. 2nd ed. New York, NY: Oxford University Press; 2004

54 Husain AM, Horn GJ, Jacobson MP. Non-convulsive status epilepticus: usefulness of clinical features in selecting patients for urgent EEG. J Neurol Neurosurg Psychiatry 2003;74(2): 189-191 